\title{
Bendectin and Birth Defects II: Ecological Analyses
}

\author{
Jeffrey S. Kutcher, ${ }^{1}$ Arnold Engle, ${ }^{2}$ Jacqueline Firth, $^{3}$ and Steven H. Lamm ${ }^{2 *}$ \\ ${ }^{1}$ University of Michigan, Department of Neurology, Ann Arbor, Michigan 48109 \\ ${ }^{2}$ Consultants in Epidemiology and Occupational Health, Inc., Washington, DC 20007 \\ ${ }^{3}$ Tulane University School of Medicine, New Orleans, Louisiana 70112
}

Received 18 May 2001; Accepted 5 December 2001

BACKGROUND: Bendectin was the primary pharmaceutical treatment of nausea and vomiting of pregnancy (NVP) in the United States until the early 1980s. Its manufacture was then discontinued after public allegations that it was causing birth defects. Subsequently, meta-analyses of the many epidemiological cohort and case/control studies used to examine that hypothesis have demonstrated the absence of a detectable teratogenic effect. This study presents an ecological analysis of the same hypothesis that examines specific malformations. METHODS: Annual birth defect prevalence data for the 1970s to the 1990s have been obtained for specific birth defects from the Center for Disease Control's nationwide Birth Defect Monitoring Program. These data for the US have been compared graphically to the annual US Bendectin sales for the treatment of NVP. Data have also been obtained for annual US rates for hospitalization for NVP. The three data sets have been temporally compared in graphic analysis. RESULTS: The temporal trends in prevalence rates for specific birth defects examined from 1970 through 1992 did not show changes that reflected the cessation of Bendectin use over the 1980-84 period. Further, the NVP hospitalization rate doubled when Bendectin use ceased. CONCLUSIONS: The population results of the ecological analyses complement the person-specific results of the epidemiological analyses in finding no evidence of a teratogenic effect from the use of Bendectin. Birth Defects Research (Part A) 67:88-97, 2003. (C) 2003 Wiley-Liss, Inc.

\section{INTRODUCTION}

From time immemorial, women have complained of the discomforts of "morning sickness," the colloquial term for the condition that is medically referred to as nausea and vomiting of pregnancy (NVP). The condition is characterized by symptoms ranging from nausea without vomiting to nausea and severe vomiting, known as hyperemesis gravidarum (HG). Severity of the condition ranges from mild-moderate to most severe. Prevalence rates of this condition among pregnant women have been reported as 50-90\% (Gadsby, 1993; Tierson et al., 1986). The onset of NVP symptoms usually occurs at about 40 days after the last menstrual period (LMP); cessation generally follows at about 85 days post-LMP. The impact of NVP on the women who suffer from it can be social and emotional as well as physical. Doctors often have differing opinions on treatments of NVP cases. They generally advise women to change their diet. Anti-emetics may also be prescribed. Severe cases of NVP may lead to hospitalization for rehydration and for treatment with anti-emetic, psychotropic, or sedating pharmaceutical agents.

In 1956, the drug Bendectin was introduced into the US market specifically for the treatment of NVP. Bendectin sales grew steadily throughout the 1960s and 1970s and it quickly became the leading treatment for NVP in the US. In the UK it was marketed as Debendox and in Germany as Lenotan. The original formulation of the drug, used until November 1976, contained dicyclomine $\mathrm{HCl}$ (an antispasmodic), doxylamine succinate (an antihistaminic), and pyridoxine $\mathrm{HCl}$ (Vitamin $\mathrm{B}_{6}$ ). The drug was reformulated in
1976 with the removal of dicyclomine (FDA Drug Bulletin, 1981; Lamm, 1984).

By 1980, one-quarter to one-third of pregnant women in the United States were using Bendectin during their pregnancy. Beginning in 1980, however, lawsuits and television programs began to allege that Bendectin was a significant human teratogen, calling it "The Second Thalidomide." Soon after this media coverage began, doctors and pregnant women nationwide became concerned about the possible effects of Bendectin use on the developing fetus, and a large number of lawsuits ensued. Plaintiffs claimed that Bendectin use had resulted in birth defects, primarily limb reduction defects, in infants exposed to Bendectin in utero. In June 1983, the manufacturer of Bendectin discontinued its production, citing the increased insurance cost of maintaining such a litigious drug on the market. Although the use of Bendectin for the treatment of NVP ceased in the US in June 1983, NVP continues to be a problem for pregnant women.

The circumstances surrounding the popularity and decline of Bendectin use provide an opportunity to examine, in an "unnatural" or "unplanned" experiment, the hypothesis that Bendectin was a significant teratogenic agent for humans. If Bendectin was a causative teratogenic agent, as has been alleged, one would expect to see an effect on nationwide rates of birth defects during this time period.

*Correspondence to: Steven H. Lamm, Consultants in Epidemiology and Occupational Health, Inc., 2428 Wisconsin Ave., NW, Washington, DC 20007. E-mail: steve@ceoh.com

Published online in Wiley InterScience (www.interscience.wiley.com). DOI: $10.1002 /$ bdra. 10034 
That is, if Bendectin were a human teratogen used by a large proportion of pregnant women, the cessation of its use should have lead to a reduced frequency of specific birth defects. The Center for Disease Control's Birth Defect Monitoring Program, including nationwide data for 197092, provided an appropriate database for examining this phenomenon. The temporal comparison of the birth prevalence rates of specific birth defects with data on Bendectin usage serves as the core analysis for this report. This is an extension of the report and analysis originally submitted to the US court system in 1984 when one of the authors (SHL) served as a court-appointed expert in epidemiology in the "Bendectin" product liability litigation (Lamm, 1984).

\section{BACKGROUND}

Numerous epidemiological studies have been conducted to investigate the possible association between birth defects and in utero exposure to Bendectin. Some of these studies have reported a statistically significant positive association between Bendectin and a specific birth defect or birth defect group (Rothman et al., 1979; Eskenazi and Bracken, 1982; Golding et al., 1983; Aselton, 1984). Other studies have reported a statistically significant negative association between Bendectin and a specific birth defect or birth defect group (Fleming et al., 1981, Mitchell et al., 1981). Most studies, however, have produced many nonsignificant findings.

Two meta-analyses have been published, both of which found that the association between Bendectin use and the prevalence of birth defects was no different from 1.0 (Einarson et al., 1988; McKeigue et al., 1994). The meta-analyses were performed both on the "all malformations" or "all major malformations" data and on "organ-specific malformations" data, based on cohort or case-control studies.

The published epidemiological studies seldom addressed specific types of malformations. Cohort studies to examine rare events need to be quite large. Case/control studies generally need an investigator with a specific interest in a specific malformation. This study provides an analysis of the relationship between Bendectin use and the birth prevalence of various specific birth defects in the United States using annual nationwide data both for Bendectin use and for specific birth defects. This is an ecological analysis, as the individual exposure characteristics of the observed cases are not known.

Nearly two decades have passed since the Bendectin era of treatment for NVP. Changes in the pharmacological treatment of NVP patients and their need for hospitalization can now be analyzed.

\section{MATERIALS AND METHODS}

To assess the temporal relationship between Bendectin usage and birth defect rates, nationwide (USA) sources for such data were sought. Three sources for measuring the temporal trend in Bendectin usage were identified: one based on drug mentions in physician office visits, one on pharmacy data, and one on manufacturing data. The nationwide birth defect surveillance system at the Center for Disease Control (CDC) provided the temporal measure of outcome (specific birth defects).

\section{Exposure Data: Bendectin Use}

Initial data on nationwide Bendectin use was gathered from three sources: 1) the National Center for Health Sta- tistics' (NCHS) National Ambulatory Medical Care Survey (NAMCS) that estimates diagnosis-specific drug mention rates for physician office visits; 2) a Merrell-Dow Pharmaceuticals, Inc. estimation of New Therapy Starts; and 3) the Food and Drug Administration (FDA) manufacturer's reports that include the number of Bendectin tablets sold per year in the United States.

Between 1980 and 1990, the National Center for Health Statistics (NCHS) conducted five surveys on medical care in ambulatory practices. These surveys, collectively known as the National Ambulatory Medical Care Survey (NAMCS), were conducted in 1980, 1981, 1985, 1989, and 1990 , and their data are available on public use data tapes from the NCHS. The NAMCS is a sample-based database of patient visits to non-federally employed physicians classified by the American Medical Association (AMA) as "office-based, patient care" physicians. Patient visit data do not include consultations outside of the physician's office, over the telephone, or in a hospital or institutional setting. The NAMCS includes information regarding all drugs or medications ordered, administered, or provided during the visit. The AMA Drug Evaluation classifications were used to identify anti-emetics (including anti-motion sickness) drugs. The specific anti-emetics prescribed for all diagnoses of normal pregnancy and NVP were recorded as "drug mentions." These included both Bendectin and nonBendectin anti-emetics used during pregnancy

An annual estimate of New Therapy Starts of Bendectin usage was developed for Merrell-Dow Pharmaceuticals, Inc. and submitted in litigation to the Southern District of Ohio United States District Court. The estimate of Bendectin New Therapy Starts was based on the 1961-1983 Bendectin data from the National Disease and Therapeutic Index (NDTI), published by IMS America, and the absence of Bendectin distribution after 1984. The NDTI contains information regarding drugs prescribed by private practitioners in the United States, include both civilian and military usage. Initial prescriptions were distinguished from repeat (follow-up) prescriptions. The New Therapy Starts data represent an annual approximation of the number of women initiating treatment with Bendectin.

Pharmaceutical companies have been required since 1974 to report annually to the US Food and Drug Administration (FDA) the number of tablets distributed for each of their products. The data that were reported to the FDA for annual Bendectin tablet distribution were obtained. These data on total US Bendectin sales (civilian plus military) were used in the analyses that follow.

\section{Outcome Data: Congenital Malformations}

Beginning in 1970, the Birth Defect Monitoring Program (BDMP) of the Centers for Disease Control and Prevention (CDC) maintained a nationwide surveillance system of birth defects. The BDMP monitored birth defect data through hospital discharge records. Annual rates for specific congenital malformations were developed using the data from this surveillance system.

The BDMP data were collected from coded hospital discharge abstract forms through either the Commission on Professional and Hospital Activities (CPHA) or the McDonald-Douglas Health Information System (MDHIS). The CPHA data on birth defects among live and stillborn newborns has, since 1970, covered 15.5 million births from 1,200 hospitals. The MDHIS data on birth defects among 
Table 1

Birth Defect Monitoring Program (BDMP) and International Classification of Disease (ICD-9) Codes Used for the Grouping of Congenital Malformations by Type

\begin{tabular}{|c|c|c|c|}
\hline Category & BDMP codes & ICD-9 codes & Malformations \\
\hline CNS & $045,054,065,090,100$ & $740-742$ & $\begin{array}{l}\text { Anencephaly, spina-bifida, hydrocephalus, } \\
\text { encephalocele, microcephalus }\end{array}$ \\
\hline Cardiac & $180,200,201,215,260$ & $745-747$ & $\begin{array}{l}\text { Transposition of great vessels, VSD, ASD, valve } \\
\text { stenosis and atresia, PDA }\end{array}$ \\
\hline Facial cleft & $325,326,327$ & $749.0-749.2$ & Cleft palate, cleft lip, cleft palate with cleft lip \\
\hline Gastro-intestinal & $375,393,395$ & $750.3,751.2$ & $\begin{array}{l}\text { Trach/esoph. Fistula, rectal atresia \& stenosis, rectal \& } \\
\text { anal dist. necrosis }\end{array}$ \\
\hline Genital tract & 412,413 & 752 & Undescended testicle, hypospadias \\
\hline Limb malformations & $472,481-483,490$ & $755.2-755.4$ & $\begin{array}{l}\text { Club foot w/o CNS defects, polydactyly, syndactyly, } \\
\text { reduction, hip dislocation }\end{array}$ \\
\hline Genetic & $626,628,630$ & $758.0-758.8$ & $\begin{array}{l}\text { Down syndrome, non-Down syndrome, autosomal } \\
\text { defect, sex chromosome defect }\end{array}$ \\
\hline Third trimester & $695,943,999$ & $771,779.9,773$ & Total monitored infections, stillbirth, $\mathrm{RH}$ hemolytic NB \\
\hline
\end{tabular}

live newborns from 1982-88 covered 2.9 million births from about 900 hospitals. The BDMP database included about $22 \%$ of the US births occurring from 1970-91. Although the BDMP is neither a random nor a representative sample of US births, it is the largest body of information on US birth defects consistently collected. The BDMP data is coded to the ICD-9-CM, modified by the British Pediatric Association adaptation. The data is reported for 161 birth defect categories. The data on 38 of these birth defect categories were considered by the CDC to have sufficient numbers to maintain statistical stability over time. Twentyfive of these 38 defect categories have been considered relevant to this study and are included in the analysis (Table 1). The outcomes have been grouped into eight distinct categories: central nervous system, cardiac, facial cleft, gastrointestinal, genital tract, limb malformations, genetic, and third trimester defects.

\section{Outcome Data: Hospitalization for NVP}

The National Center for Health Statistics develops annually a public use data tape of hospital discharge data. These data are from non-institutional (short-stay general and specialty) hospitals, exclusive of military and Veterans Administration hospitals, located in the 50 states and the District of Columbia. These data tapes can be used to determine the annual estimated frequency of hospitalizations for NVP or HG (coded as 643, i.e., excessive vomiting in pregnancy).

\section{Analytic Methods}

This study presents an ecological graphic analysis of temporal data for Bendectin use, birth defect birth prevalence rates, and hospitalizations for NVP that covers both the time period when Bendectin was the major pharmacologic treatment for NVP and the time period when Bendectin was no longer available in the United States. As mentioned earlier, three measures of Bendectin usage or exposure are available for comparison. The annual data on Bendectin New Therapy Starts and on Bendectin tablet sales are available as continuous data. The data on antiemetic use for NVP from the NAMCS is only available as intermittent data in the 1980-90 time period. The trends in Bendectin use represented by these three data sets are compared graphically in Figure 1.
The US birth prevalence of individual birth defects are presented in temporal graphic analyses (Figs. 2-9) as continuous annual data. The specific birth defects are organized and presented by groups, such as organ systems. Within each group, the temporal patterns of the specific birth defects are compared graphically with the temporal pattern of Bendectin sales data, which are used as a measure of the usage of Bendectin in the US.

A comparison of all anti-emetic treatments for NVP is given to show the use of Bendectin in comparison with other anti-emetics (Fig. 10). The annual US rate of hospitalization for NVP is also presented as a temporal graphic analysis of continuous annual data (Fig. 11). Finally, the temporal patterns of the Bendectin usage, the birth defect data, and the hospitalizations for NVP are graphically compared (Fig. 12).

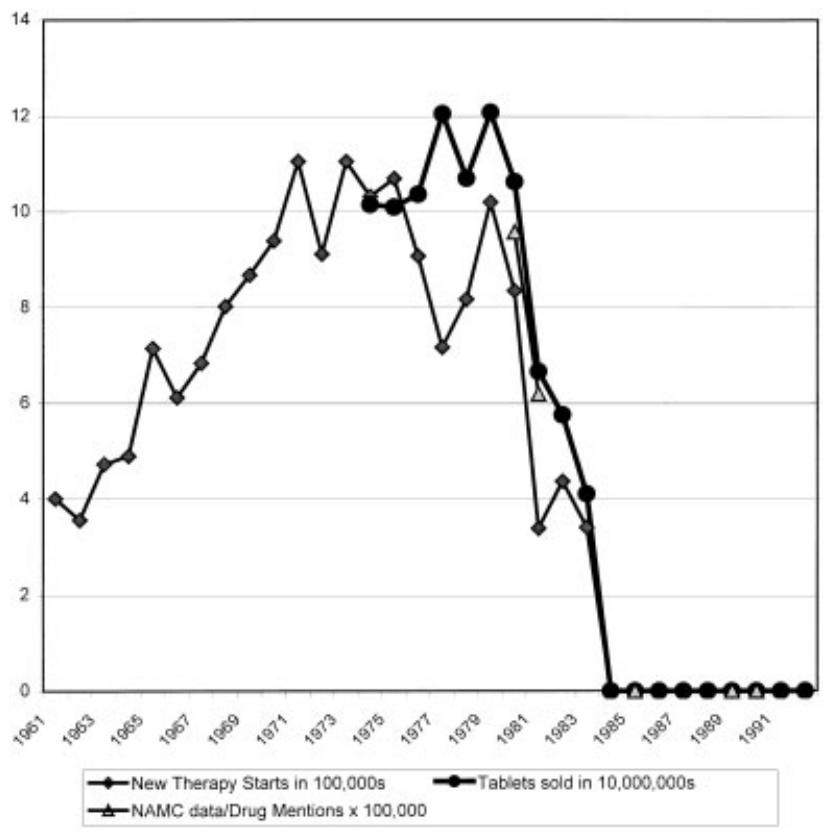

Figure 1. Temporal patterns of Bendectin use in the United States, 1970-92. 
Table 2

Percent Change in Incidence of Birth Defects from 1970-1992*

\begin{tabular}{|c|c|c|c|c|}
\hline Congenital anomaly & Min. & Max. & Mean & $\begin{array}{c}\text { Change } \\
\text { 1970-1992 }\end{array}$ \\
\hline \multicolumn{5}{|l|}{ Central nervous system } \\
\hline Anencephaly & 1.1 & 5.6 & 3.3 & $-71 \%$ \\
\hline Spina bifida & 3.7 & 8.3 & 5.3 & $-51 \%$ \\
\hline Hydrocephalus & 4.5 & 6.7 & 5.7 & $-11 \%$ \\
\hline Encephalocele & 0.8 & 1.4 & 1.3 & $9 \%$ \\
\hline Microcephalus & 1.1 & 3.7 & 2.4 & $53 \%$ \\
\hline \multicolumn{5}{|l|}{ Cardiac } \\
\hline Transposition of great vessels & 0.6 & 2.9 & 1.3 & $383 \%$ \\
\hline Ventricular septal defect/2,500 births & 1.0 & 7.3 & 3.6 & $633 \%$ \\
\hline Atrial septal defect & 1.2 & 14.4 & 3.6 & $658 \%$ \\
\hline Valve stenosis and atresia & 1 & 7.3 & 3.3 & $564 \%$ \\
\hline Patent ductus arteriosus $/ 2,500$ births & 0.9 & 16.2 & 6.4 & $1751 \%$ \\
\hline \multicolumn{5}{|l|}{ Facial clefts } \\
\hline Cleft palate without cleft lip & 4.6 & 5.9 & 5.3 & $4 \%$ \\
\hline Cleft lip without cleft palate & 3.0 & 4.2 & 3.5 & $-3 \%$ \\
\hline Cleft palate with cleft lip & 4.1 & 6.3 & 5.7 & $2 \%$ \\
\hline \multicolumn{5}{|l|}{ Gastro-intestinal } \\
\hline Tracheo-esophageal fistula & 1.4 & 3.4 & 2.1 & $79 \%$ \\
\hline Rectal atresia and stenosis & 3.0 & 4.2 & 3.6 & $20 \%$ \\
\hline \multicolumn{5}{|l|}{ Genital tract } \\
\hline Undescended testicle/2,500 births & 4.8 & 10.5 & 7.4 & $112 \%$ \\
\hline Hypospadias/2,500 births & 5.1 & 9.2 & 7.0 & $73 \%$ \\
\hline \multicolumn{5}{|l|}{ Limb malformations } \\
\hline Clubfoot w/o CNS/5,000 births & 11.6 & 15.9 & 12.7 & $-2 \%$ \\
\hline Polydactyly/5,000 births & 8.7 & 13.2 & 10.8 & $25 \%$ \\
\hline Syndactyly & 5.3 & 8.3 & 6.7 & $45 \%$ \\
\hline Reduction deformities & 3.0 & 4.0 & 3.5 & $18 \%$ \\
\hline Hip dislocation and subluxation & 7 & 37.6 & 25 & $291 \%$ \\
\hline \multicolumn{5}{|l|}{ Genetic } \\
\hline Down syndrome/2,500 births & 7.4 & 10.5 & 8.6 & $30 \%$ \\
\hline Non-Down autosomal/2,500 births & 1.0 & 3.3 & 2.0 & $200 \%$ \\
\hline Sex chromosome defect/2,500 births & 0.5 & 1.7 & 0.9 & $100 \%$ \\
\hline \multicolumn{5}{|l|}{ Third Trimester Outcomes } \\
\hline Monitored infections & 3.1 & 15.0 & 6.1 & $220 \%$ \\
\hline Rh hemolytic disease/2,500 births & 3.0 & 11.2 & 4.9 & $-71 \%$ \\
\hline Stillbirth/1,000 births & 2.0 & 12.1 & 7.4 & $-81 \%$ \\
\hline
\end{tabular}

*Summary data from the Birth Defect Monitoring Program, by malformation type. Birth prevalence per 10,000 births unless otherwise specified.

\section{RESULTS \\ Measures of Bendectin Usage}

The temporal patterns of Bendectin use are presented in Figure 1. All three data sources, the NAMC drug mention data, New Therapy Starts, and the number of tablets sold, show a similar downward trend of usage from 1980-84.

Bendectin sales data are a direct measure of the annual sales of Bendectin, whereas New Therapy Starts and drug mentions are estimated data. By definition, Bendectin sales data are the number of tablets distributed from the manufacturing plant annually for domestic consumption. New Therapy Starts are a calculated annual estimate based on prescription data from a varying set of pharmacies, and drug mentions are a calculated intermittent estimate on a statistical sampling of physician's offices. Despite the different ways in which these data were gathered, the three measures of Bendectin use present a consistent temporal pattern of Bendectin use in the US for the 1970s and 1980s.

\section{Congenital Malformations and Bendectin Use}

Table 2 summarizes the general upward or downward trends in the birth prevalence rates of birth defects from
1970 to 1992, according to the BDMP data. The birth prevalence rate for each malformation has been reported by BDMP for each year. The range of the annual birth prevalence rates for each specific malformation is shown as well as the mean birth prevalence rate. The gross temporal change in reported rates over the 23-year period is shown for each specific malformation. Some malformation groups, e.g., facial clefts, show no change in prevalence over the time period. A few recorded malformations showed a major reduction over the time interval. These malformations included certain CNS malformations, such as anencephaly $(-71 \%)$ and spina bifida $(-51 \%)$, which are first-trimester events, and stillbirths $(-81 \%)$, which is classified as a third trimester condition. Others, such as cardiac defects, show marked increases in reported rates. The strongest upward trends were for cardiac malformations, especially the transposition of great vessels $(383 \%)$, ventricular septal defect $(633 \%)$, and patent ductus arteriosus $(1,751 \%)$.

Whereas Table 2 reports on the general trend in malformation reports over the extended time period, Table 3 examines the Bendectin hypothesis by comparing the prevalence rates before and after the dramatic downturn in 
Table 3

Rates of Birth Defects During and Post-Bendectin Era*

\begin{tabular}{|c|c|c|c|}
\hline Congenital anomaly & $\begin{array}{c}\text { Bendectin Era } \\
1978-1980\end{array}$ & $\begin{array}{c}\text { Post-Bendectin } \\
\text { 1985-1987 }\end{array}$ & $\begin{array}{l}\text { Change in birth } \\
\text { prevalence }\end{array}$ \\
\hline \multicolumn{4}{|l|}{ Central nervous system } \\
\hline Anencephaly & 3.53 & 2.43 & $-31 \%$ \\
\hline Spina bitida & 5.30 & 4.63 & $-13 \%$ \\
\hline Hydrocephalus & 5.07 & 6.33 & $25 \%$ \\
\hline Encephalocele & 1.17 & 1.10 & $-6 \%$ \\
\hline Microcephalus & 2.17 & 2.60 & $20 \%$ \\
\hline \multicolumn{4}{|l|}{ Cardiac } \\
\hline Transposition of the great vessel & 0.90 & 1.50 & $67 \%$ \\
\hline Ventricular septal defect & 10.80 & 20.13 & $86 \%$ \\
\hline Atrial septal defect & 1.30 & 3.43 & $164 \%$ \\
\hline Valve stenosis and atresia & 1.37 & 5.47 & $299 \%$ \\
\hline Patent ductus arteriosus & 15.63 & 35.17 & $125 \%$ \\
\hline \multicolumn{4}{|l|}{ Facial clefts } \\
\hline Cleft palate w/o cleft lip & 5 & 5.6 & $12 \%$ \\
\hline Cleft lip w/o cleft palate & 3.5 & 3.4 & $-2 \%$ \\
\hline Cleft lip w/cleft palate & 4.6 & 5.9 & $28 \%$ \\
\hline \multicolumn{4}{|l|}{ Gastrointestinal } \\
\hline Tracheo-esophageal fistula & 1.73 & 2.57 & $49 \%$ \\
\hline Rectal atresia and stenosis & 3.23 & 3.87 & $20 \%$ \\
\hline \multicolumn{4}{|l|}{ Genital } \\
\hline Undescended testicles & 24.47 & 36.10 & $48 \%$ \\
\hline Hypospadias & 30.00 & 32.70 & $9 \%$ \\
\hline \multicolumn{4}{|l|}{ Limb } \\
\hline Clubfoot w/o CNS defects & 24.90 & 25.33 & $2 \%$ \\
\hline Polydactyly & 20.67 & 23.20 & $12 \%$ \\
\hline Syndactyly & 6.57 & 7.47 & $14 \%$ \\
\hline Reduction deformity & 3.53 & 3.83 & $8 \%$ \\
\hline Hip dislocation and subluxation & 28.40 & 29.93 & $5 \%$ \\
\hline \multicolumn{4}{|l|}{ Genetic } \\
\hline Down syndrome & 7.77 & 9.57 & $23 \%$ \\
\hline Autosomal abnormality (non-Down) & 1.50 & 2.67 & $78 \%$ \\
\hline Sex chromosome defect & 0.70 & 1.20 & $60 \%$ \\
\hline \multicolumn{4}{|l|}{ Third trimester } \\
\hline Total monitored infections & 3.47 & 5.97 & $72 \%$ \\
\hline Rh hemolytic disease & 15.33 & 14.93 & $-3 \%$ \\
\hline Stillbirth & 83.83 & 57.47 & $-31 \%$ \\
\hline
\end{tabular}

*Summary data from the Birth Defect Monitoring Program, by malformation type. Birth prevalence per 10,000 births unless otherwise specified.

Bendectin use. The birth defect rates during two specific time periods are compared: the rate during the height of the Bendectin era (1978-80) and the rate after its discontinuation (1985-87). The percent change from the first period to the second period is also given.

In the original presentation of these analyses to the Court, New Therapy Starts had been used as the representative measure of the temporal pattern of Bendectin use these data had been certified by the manufacturer and accepted as representative upon submission to the Court. Examples of those graphic analyses have been recently published by Brent (2001) can be compared to those presented here. In this ecological analysis, however, Bendectin sales data was used as the measure of Bendectin use, because: 1) the sales data were developed independent of the judicial proceedings, and 2) it was collected contemporaneously by the Food and Drug Administration each year. Figure 1 demonstrated that the temporal patterns of the two continuous measures are similar.

The NAMCS data was not used in the Court or in this analysis as the measure of the temporal pattern of Bendectin usage as it is relatively intermittent data (five data points in 11 years). Nonetheless, its pattern is consistent with those of the other two measures.

Figures 2-9 show ecologically the patterns of the birth prevalence of each specific birth defect malformation graphed over time in comparison to the temporal trend of Bendectin sales as a measure of Bendectin usage.

\section{Central Nervous System Malformations}

Figure 2 demonstrates a noticeable decrease in CNS malformations in the United States between 1970-92. Specifically, both anencephaly $(-71 \%)$ and spina bifida $(-51 \%)$ show a large and continuous decrease, whereas encephalocele shows a slight increase $(9 \%)$. The annual incidences of both anencephaly and spina bifida were declining between 1970-79, a period during which Bendectin sales did not show a similar decline. None of the monitored central nervous system malformations show a temporal pattern consistent with that of Bendectin use. Across the period during which Bendectin came off the market, notable decreases in anencephaly and spina bi- 


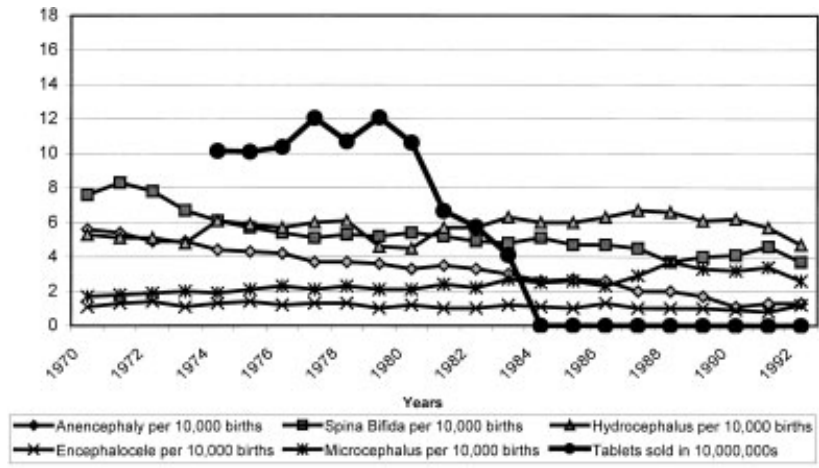

Figure 2. Incidence of central nervous system defects (BDMP) and Bendectin tablet sales in the United States, 1970-92.

fida rates were observed as were increases in the rates for hydrocephalus and microcephalus.

\section{Cardiac Malformations}

Figure 3 demonstrates a steady increase in cardiovascular malformations from 1970-92. All three malformations show a significant increase, with patent ductus arteriosus (PDA) rising 1,751\% between 1970-92. These increases are in direct opposition to the decline in Bendectin sales. Although most of the cardiac defects were being reported more frequently throughout the entire period, none of these rates of increase was reflected downward contemporaneously with the drop in Bendectin use.

\section{Facial Cleft Defects}

Figure 4 demonstrates that each facial cleft defect incidence rate remained relatively unchanged between 1970 92. Both cleft palate (4\%) and cleft palate with cleft lip (2\%) showed minor increases, whereas cleft lip showed a $3 \%$ decrease.

\section{Gastrointestinal Defects}

Figure 5 demonstrates an increase in the annual incidences of both tracheoesophageal fistulae (79\%) and rectal

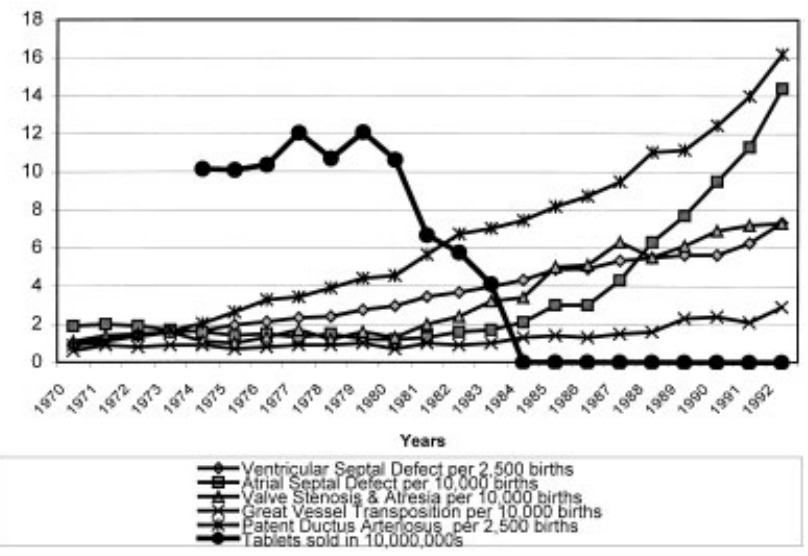

Figure 3. Incidence of cardiac defects (BDMP) and Bendectin tablet sales in the United States, 1970-92.

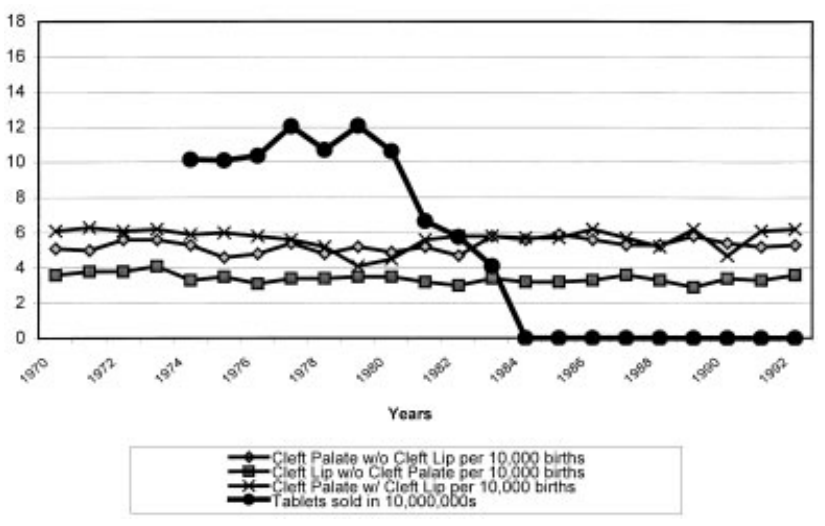

Figure 4. Incidence of facial anomalies (BDMP) and Bendectin tablet sales in the United States, 1970-92.

atresia and stenoses (20\%) between the years 1970-92. Neither of these trends resembles the Bendectin sales data.

\section{Genital Tract Malformations}

Figure 6 demonstrates a slight but steady increase in the incidence of genital tract malformation from 1970-92. Both undescended testicle $(112 \%)$ and hypospadias (73\%) showed increases that do not resemble the drop in Bendectin sales.

\section{Limb Malformations}

Figure 7 demonstrates that, of the limb malformations analyzed, only clubfoot without CNS defects showed a decrease (2\%) in annual incidence between 1970-92. Polydactyly (25\%), syndactyly (45\%), and limb reduction (18\%) each showed a notable increase. Hip dislocation and subluxation showed a jagged increase in between 1974-79 that declined sharply before the drop in Bendectin sales and began to climb again after the cessation of its use; overall hip dislocation and subluxation showed a dramatic $291 \%$ increase between 1970-92. None of these trends indicate a pattern similar to Bendectin sales.

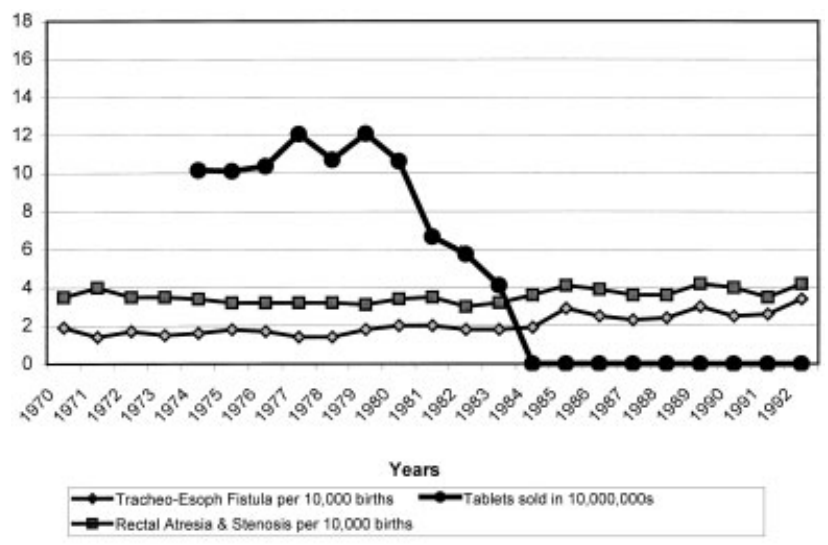

Figure 5. Incidence of gastrointestinal defects (BDMP) and Bendectin tablet sales in the United States, 1970-92. 


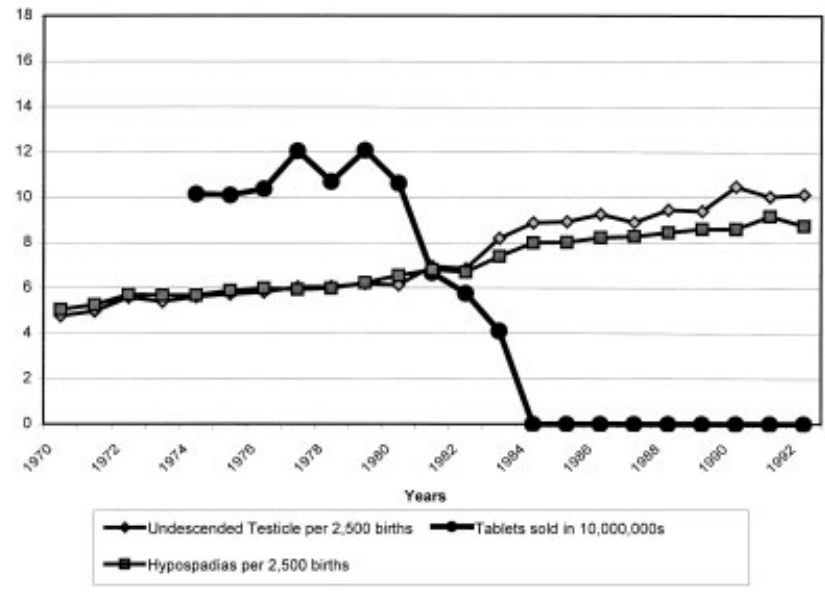

Figure 6. Incidence of genital defects (BDMP) and Bendectin tablet sales in the United States, 1970-92.

\section{Genetic Malformations}

Figure 8 demonstrates an increase in the incidence of Down syndrome $(30 \%)$, autosomal abnormalities excluding Down syndrome (200\%), and sex chromosome abnormalities (100\%) in the US from 1970-92. These increases do not resemble the dramatic decrease in Bendectin sales seen around 1980.

\section{Third Trimester Defects}

Figure 9 demonstrates that, although the annual incidence of monitored infections increased $220 \%$, this increase occurred during 1987-1991. The incidence of Rh hemolytic disease $(71 \%)$ and stillbirths $(81 \%)$ both show steady declines in the US between the years of 1970-92. The decrease in $\mathrm{Rh}$ hemolytic disease occurs primarily before 1980 . The incidence of stillbirth has been declining steadily since 1970.

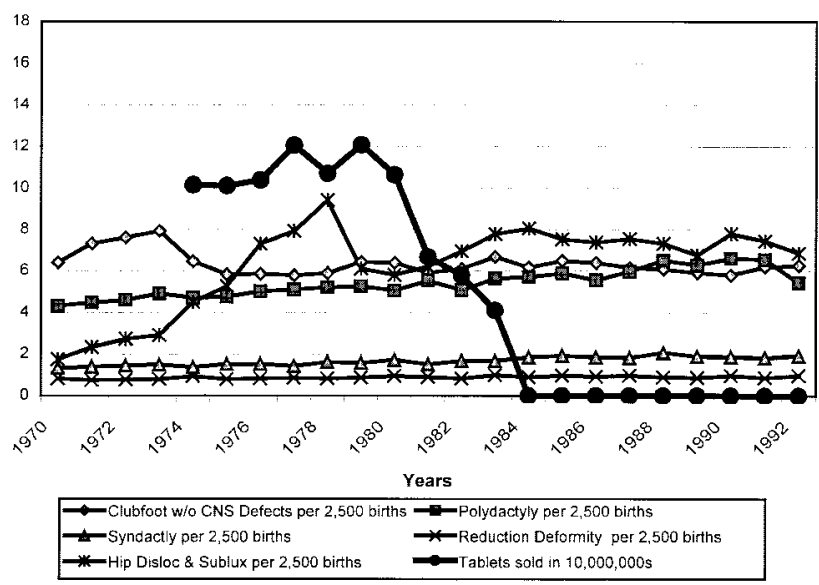

Figure 7. Incidence of limb malformations (BDMP) and Bendectin tablet sales in the United States, 1970-92.

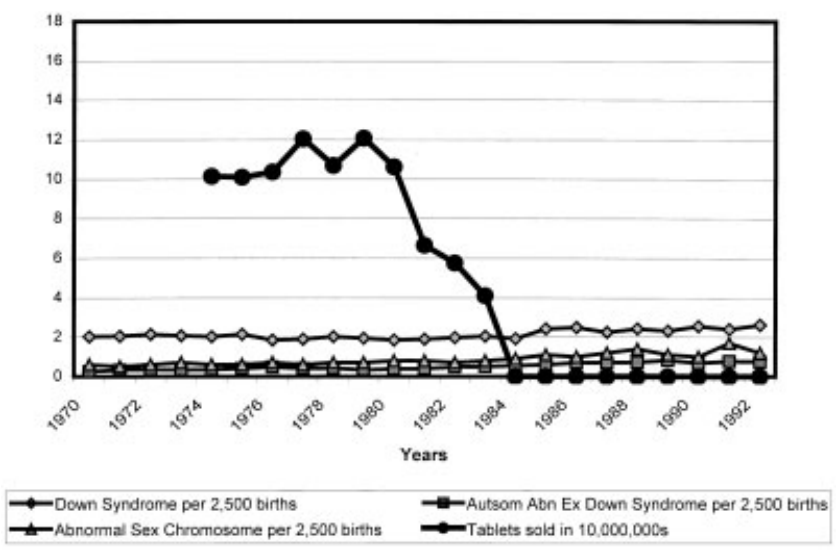

Figure 8. Incidence of genetic defects (BDMP) and Bendectin tablet sales in the United States, 1970-92.

\section{Anti-Emetic Use in Pregnancy: During and Post-Bendectin Era}

The National Ambulatory Medical Care Survey (NAMCS) provides an intermittent view of the use of anti-emetics during pregnancy (1980-90), including both use of Bendectin and non-Bendectin anti-emetics. The 1980 survey indicated that Bendectin accounted for $82 \%$ of the anti-emetic use for NVP $(479,650$ of 584,452 drug mentions). The 1981 survey indicated that Bendectin accounted for $74.6 \%$ of the anti-emetic use for NVP $(310,214$ of 415,657 drug mentions). Bendectin was not mentioned in the anti-emetic use for NVP data in the NAMCS reports for 1985,1989 , or 1990, although those surveys had drug mention numbers of 69,683 for 1985, 103,592 for 1989 , and 64,555 for 1990 . Figure 10 demonstrates the marked drop between 1981-85 in anti-emetic treatment for NVP. The use of anti-emetics dropped about $90 \%$ between $1980-85$, essentially due to the absence of Bendectin. The subsequent anti-emetic use has remained at about 80,000 women per year, according to the NAMCS data. Compazine, Phenergan, and Dramamine were the major non-Bendectin anti-emetics

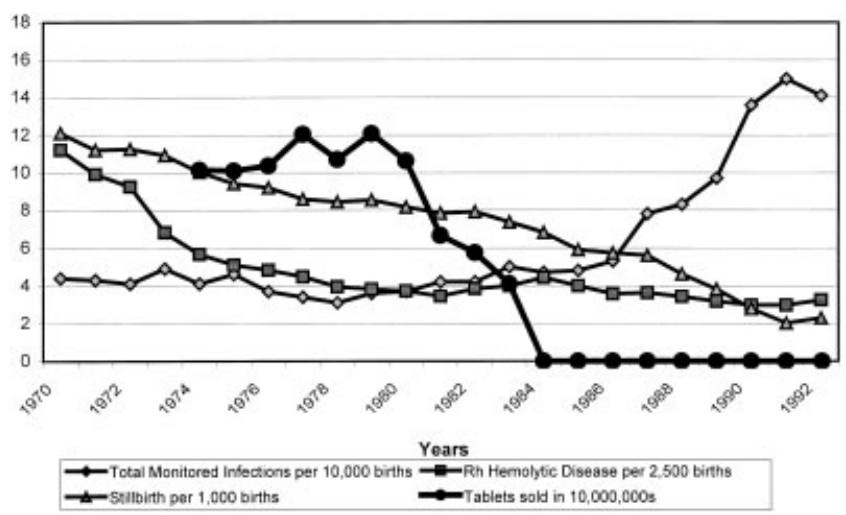

Figure 9. Incidence of third trimester defects (BDMP) and Bendectin tablet sales in the United States, 1970-92. 


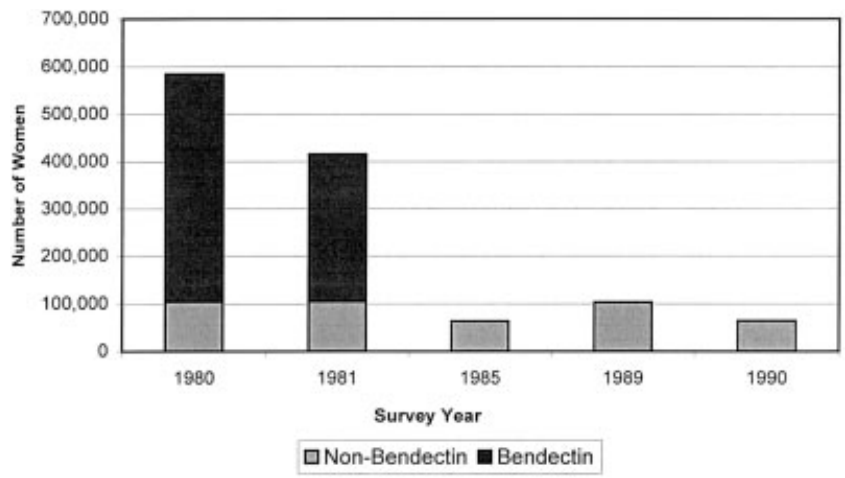

Figure 10. Anti-emetic treatments for nausea and vomiting of pregnancy (National Ambulatory Medical Care Surveys [1980-90] Drug Mentions).

cited. It is clear that the use of other anti-emetics did not replace Bendectin in the treatment of NVP in the US.

\section{Hospitalization Data for NVP: During and Post-Bendectin Era}

The NCHS public use data tapes on hospitalizations have been analyzed to determine the annual estimated number of hospitalizations for NVP in the US for the years 1974-94 (Fig. 11). From 1974-80, the number of hospitalizations for NVP has stayed remarkably steady at about seven hospitalizations per 1,000 live births. From 1980-87, the number of hospitalizations for NVP7 climbed steadily from seven per 1,000 live births to about $15-16$ per 1,000 live births. Subsequently, the rate has risen and fallen in the range of $16-17$ per 1,000 live births.

\section{Bendectin Sales, Birth Defects, and NVP Hospitalizations: During and Post-Bendectin Era}

Three measures related to Bendectin therapy have been examined temporally from the mid 1970s to the 1990s: the sales of Bendectin, the prevalence of specific birth defects, and the hospitalization rate for NVP. Figure 12 presents all three simultaneously, with limb reduction defects representing birth defect prevalence. The three measures are all data collected contemporaneously by government agencies in the ordinary conduct of their work and independent of

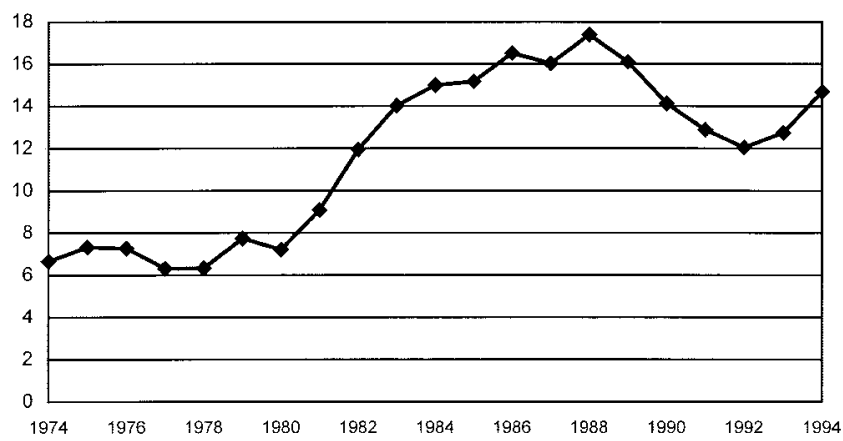

Figure 11. NVP hospitalizations in US per 1,000 live births by year (1974-90).

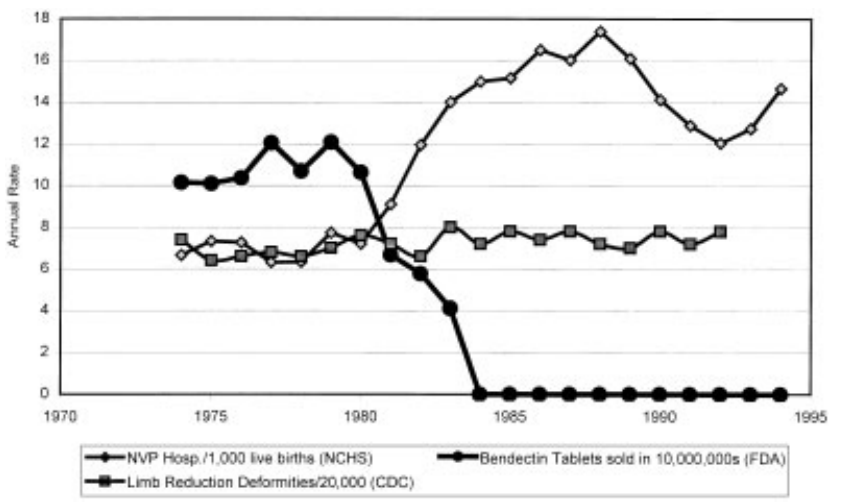

Figure 12. Public health data related to Bendectin therapy.

the hypotheses examined here. The birth defect data were collected by the Centers for Disease Control (CDC), and the Bendectin sales data were collected by the Food and Drug Administration (FDA). The National Hospital Discharge Survey data were collected by the National Center for Health Statistics (NCHS). This figure demonstrates that concomitant with the withdrawal of Bendectin from the marketplace and in the absence of a replacement, the rate of NVP hospitalization doubled and the birth defect rate (represented by limb reduction defects) remained steady.

\section{DISCUSSION}

The ecological investigation presented above was undertaken with the assumption that if Bendectin were a causal teratogenic agent, its discontinuation would have had a noticeable contemporaneous effect on the birth prevalence rates of associated birth defects in the US. Despite the numerous limitations inherent in any ecological investigation, the lack of any evidence of a decrease in the incidence of birth defects, in general or specifically, contemporaneously with the decrease and subsequent cessation of Bendectin use in the US suggests the lack of an association.

It is recognized that many factors contribute to the annual birth prevalence of birth defects. The increasing availability of screening techniques (e.g., alpha-fetal protein measures), pre-natal diagnostic capabilities (e.g., chorionic villa sampling, amniocentesis, and high contrast ultrasound), availability of first and second trimester induced abortions, and increased use of folic acid all may be reflected in the decreasing birth prevalence rates for specific malformations. Long-term changes in the reported rates reflect both increased interest in the diagnosis and reporting of birth defects as well as changes in medical practice and social policies that are directed toward the reduced frequency of birth defects and to other aspects of reproductive health. The decrease seen in the birth prevalence of nervous system disorders most likely reflects the consequences of screening programs for anencephaly and spina bifida and subsequent decisions of parents to terminate a pregnancy after alpha-fetal protein and ultrasound screening lead to a diagnosis of these conditions. Increases in the sensitivity of neonatal diagnostic equipment to detect and diagnose cardiac variations have probably led to their greater diagnostic frequency and often to therapeutic assistance. Neonatal diagnostic capabilities, particularly in 


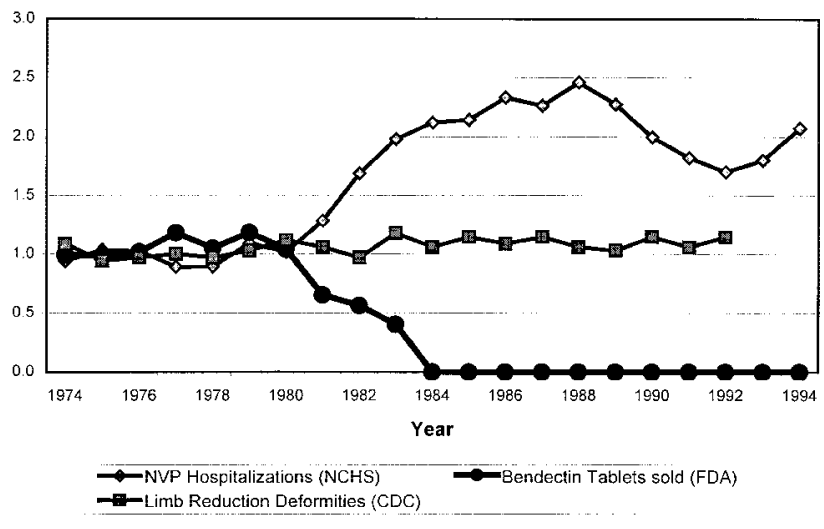

Figure 13. The Trident graph. Public health data related to Bendectin therapy (normalized to 1974-76).

neonatal cardiology, are clearly reflected in the increased frequency of reported cardiac defects seen after 1980 .

The National Ambulatory Medical Care Survey data demonstrate that the decrease in the use of Bendectin was not followed by a concomitant rise in the use of other anti-emetic agents (Engle and Lamm, 1989; Jick and Garrison, 1986). Thus, the lack of a decrease in the birth prevalence rate for limb reduction defects with the cessation of Bendectin use cannot be explained by the substitution of the use of an alternative and teratogenic anti-emetic. The National Hospital Discharge Survey data demonstrate that the US hospitalization rate for NVP doubled after the reduction and subsequent cessation of Bendectin use. The pattern of NVP hospitalization in Canada was similar to that seen in the US when Bendectin sales also disappeared from their marketplace during the $1980-85$ period. In Canada, however, Diclectin, a generic form of Bendectin, remained on the market and in the 1990s, as the sales of Diclectin markedly increased, the rate of NVP hospitalization continued to fall (Neutel, 2000). The NVP hospitalization patterns suggest that at a population level the use of Bendectin or of Diclectin had been effective in the treatment of NVP.

The development of data for ecological analyses attempts to present results in a comparable manner. Figure 13 presents the Bendectin use, birth defect prevalence rates, and NVP hospitalization rates temporally and comparably by normalizing each data set to the mean data for the years $1974-76$ as a base period. Limb reduction was used as the representative birth defect, because limb reduction was the most common of the teratological claims against Bendectin and the publicly hypothesized association, based on public knowledge of the effects of Thalidomide. The specific limb reduction defect phocomelia, the major birth defect associated with Thalidomide, has become considered publicly as the sentinel defect of druginduced teratogenicity.

Figure 13 demonstrates that, despite the reduction and cessation of Bendectin sales during the period of 1980-85, the rate of birth defects (limb reduction defect) was unaffected and the rate of NVP hospitalization doubled. This graphic presentation of the temporal pattern of the public health data lends itself to the interpretation that the ecological data indicated that the Bendectin therapeutic regi- men was both safe (no effect on birth defect prevalence) and effective (doubling of NVP hospitalization rate). This interpretation is, of course, open to the proviso that it is based on an ecological presentation where the specific exposure status of each case and each non-case is unknown, i.e., susceptible to the ecological fallacy. Nonetheless, the pattern is quite consistent with the known purpose for which the drug was taken and with the epidemiological studies that have shown no teratological association.

Although the data presented here may be interpreted in a variety of ways, this analysis was not designed to investigate a direct causal relationship between Bendectin use and specific congenital malformations, but rather to examine the trend of birth defects relative to the usage of Bendectin. The lack of a decrease in the birth prevalence of birth defects concomitant with the decrease and subsequent cessation of Bendectin use does not support the previously hypothesized association between Bendectin and birth defects.

Although an ecological analysis, such as the one presented above, does not contain the statistical precision often found in a case/control or cohort study, this analysis does provide an exploratory investigation into possible relationships between Bendectin use and incidence of birth defects by making use of the best available national data. Epidemiologists tend to be more influenced by case/control and cohort studies in reaching a judgment that a particular exposure is, or is not, related to a particular outcome. With respect to the Bendectin/birth defect hypothesis, the published meta-analyses of the case/control and cohort studies (Einarson et al., 1988; McKeigue et al., 1994) convinced the professional and regulatory communities to conclude that the data did not support the causal hypothesis. In presenting the information to non-medical audiences, ecological analyses are often more persuasive than meta-analyses. In judicial hearings, where both the epidemiological and ecological analyses of the Bendectin data have been presented, the Court and the jury have commented afterwards that the ecological analyses were most meaningful for them. Judge Carl Rubin, for whom the report was originally written, has described the graph of the temporal patterns of Bendectin usage and limb malformations (see version published by Brent (2001) as the most effective exhibit seen in his court; the jurors from the trial also identified it as a decisive item in their determination that Bendectin was not a human teratogen.

Too often, epidemiologists speak of "ecological fallacies" without giving appropriate recognition to "ecological truths." Ecological analyses serve an important and complementary role with epidemiological analyses in presenting public health information.

\section{LITERATURE CITED}

Aselton P, Jick H, Chentow SJ, Perera DR, Hunter JH. 1984. Pyloric stenosis and maternal Bendectin exposure. Am J Epidemiol 120:251.

Brent RL. 2001. The history of the editorship of teratology during the period from July 1, 1976 to January 1, 1993. Teratology 63:100-105.

Einarson TR, Leeder JS, Koren G. 1988. A method for meta-analysis of epidemiological studies. Drug Intell Clin Pharm 22:813-824.

Engel A, Lamm SH. 1989. Temporal changes in drug use during pregnancy 1980-85, USA. J Clin Res Drug Dev 3:209.

Eskenazi B, Bracken MB. 1982. Bendectin (Debendox) as a risk factor for pyloric stenosis. Am J Obstet Gynecol 144:919-924.

FDA Drug Bulletin, Volume 11, Number 1 (March 1981) at p. 1.

Fleming DM, Knox JDE, Crombie DL. 1981. Debendox in early pregnancy and fetal malformation. BMJ 283:99-101. 
Gadsby R, Barnie-Adshead AM, Jagger CA. 1993. Prospective study of nausea and vomiting in pregnancy. Br J Gen Pract 43:245-248.

Golding J, Vivian S, Baldwin JA. 1983. Maternal anti-nauseants and cleft of lip and palate. Human Toxicol 2:63-73.

Jick SS, Garrison JM. 1988. Discontinuation of Bendectin (letter). Am J Pub Health 78:322

Lamm SH. 1984. Bendectin: final report. Submitted through Samuel H. Porter, guardium ad litem, to Judge Carl Rubin, US District Court for the Southern District of Ohio. In re: Richardson-Merrell, Inc.: “Bendectin" Product Liability Litigation, MDL No. 486.

McKeigue PM, Lamm SH, Linn S, Kutcher JS. 1994. Bendectin and birth defects: I. a meta-analysis of the epidemiologic studies. Teratology 50:27-37.
Mitchell A, Rosenberg L, Shapiro S, Slone D. 1981. Birth defects related to Bendectin use in pregnancy. I. Oral clefts and cardiac defects. JAMA 245:2311-2314.

Neutel CI. 2000. Variation in rates of hospitalization for excessive vomiting in pregnancy by Bendectin/Diclectin use in Canada. Nausea and vomiting of pregnancy: state of the art 2000. Toronto: Motherisk, the Hospital for Sick Children 1:54-59.

Rothman KJ, Fyler DC, Goldblatt A, Kreidberg MB. 1979. Exogenous hormones and other drug exposures of children with congenital heart disease. Am J Epidemiol 109:433-439.

Tierson FD. 1986. Nausea and vomiting of pregnancy and association with pregnancy outcome. Am J Obstet Gynecol 155:1017-1022. 